\title{
Los legados de la Provincia de Costa Rica ante el I Imperio mexicano durante la coyuntura independentista (1821-1823)
}

Tomás Federico Arias Castro*

https://doi.org/10.35242/RDE $2021 \quad 32 \quad 1$

Nota del Consejo Editorial

Recepción: 28 de junio de 2021

Revisión, corrección y aprobación: 5 de julio de 2021.

Resumen: El artículo expone un pormenorizado recuento de los episodios, particularidades, sucesos e incidencias de naturaleza histórica, política y jurídica que acontecieron durante la época decimonónica en que se fraguó y materializó la independencia del territorio colonial de Costa Rica respecto del Imperio español, y que se erigieron, a su vez, en los antecedentes directos para la posterior conjunción del territorio costarricense con el I Imperio mexicano. Así, se describen los acontecimientos que propiciaron la ruptura entre España y sus posesiones ultramarinas, las variables que provocaron el desencadenamiento de los procesos autonomistas novohispanos, los factores que conllevaron el nexo político entre los territorios de México y Costa Rica y, con especial significancia, los derroteros personales y públicos de los tres costarricenses que fungieron, desde distintas perspectivas y realidades, como nuestros representantes ante el citado régimen imperial mexicano. Por último, se analizan las diversas razones que produjeron el contundente fenecimiento de dicho vínculo político y los periplos posteriores de los tres legados referidos, todos ello con el fin de que pueda conocerse los detalles de uno de los hechos menos conocidos de nuestra historia.

Palabras clave: Independencia / Historia política / Autonomía / Soberanía / Libertad / Costa Rica / México.

Abstract: This research article presents a detailed account of the episodes, particularities, events and incidents of a historical, political and legal nature that occurred during the nineteenth century in which the independence of the colonial territory of Costa Rica was forged and materialized with respect to the Spanish Empire and which became the direct antecedents for the later conjunction of the Costa Rican territory with the First Mexican Empire. Thus, the events that led to the rupture between Spain and its overseas possessions are described, the variables that led to the unleashing of the autonomist processes of New Spain, the factors that led to the political nexus between the territories of Mexico and Costa Rica and, with special significance, the personal and public paths of the three Costa Ricans who served, from different perspectives and realities, as our representatives before the aforementioned Mexican imperial regime. Finally, the article presents an analysis of the various reasons that produced the overwhelming demise of this political link.

Key Words: Independence / Political history / Autonomy / Sovereignty / Freedom / Costa Rica / Mexico.

\footnotetext{
* Costarricense, doctorando en Derecho Constitucional; maestría en Ciencias Políticas y licenciado en Derecho. Correo: tomas.crmx@gmail.com. Docente de la Cátedra de Historia del Derecho de la Facultad de Derecho de la Universidad de Costa Rica, de Historia bilateral entre las Repúblicas de Costa Rica y México (con énfasis en el siglo XIX y la Revolución Mexicana) en el programa de extensión docente de la Escuela de Estudios Generales de la Universidad de Costa Rica, de Teoría del Estado en la Maestría en Diplomacia del Ministerio de Relaciones Exteriores y de Historia del Derecho Costarricense en la Universidad Escuela Libre de Derecho. Presidente del Consejo Directivo de la Editorial Costa Rica en representación de la Universidad de Costa Rica. Presidente de la Academia Costarricense de Ciencias Genealógicas. Integrante de la Comisión Nacional de Conmemoraciones Históricas. Académico de Número de la Academia Morista Costarricense. Miembro de la Asociación de Genealogía e Historia de Costa Rica y de la Asociación La Tertulia del 56 para el estudio y análisis de la Campaña Nacional 1856-1857. Integrante de la Sociedad de Amigos de la Academia Mexicana de la Historia
} 


\section{DERECHO EIECTORAL}

\section{INTROITO}

Se encuentra Costa Rica conmemorando en 2021 el valioso bicentenario de la gesta que propició su independencia respecto de la Corona española, lo cual ha servido, entre otros muchos aspectos, para desarrollar un vasto conjunto de investigaciones y estudios sobre los distintos personajes que participaron en aquella época.

Empero, con excepción de aquellos que por sus profesiones o labores se han ocupado del desciframiento de nuestro pasado (historiadores, académicos, docentes, archivistas, etc.), resulta muy poco conocida la significativa circunstancia de que, tras nuestra declaratoria de emancipación, las autoridades del entonces territorio de la Provincia de Costa Rica tomaron la decisión de unirse políticamente al también recién conformado I Imperio mexicano, lo cual devino en una determinante serie de implicaciones para nuestro país.

Este nexo fue el resultado directo de numerosos factores geopolíticos que se concatenaron en México y Centroamérica en general, así como en el plano costarricense en particular, lo cual conllevó, entonces, que nuestros dirigentes se enfocasen a la escogencia de los individuos que nos representarían ante los órganos político-administrativos imperiales mexicanos. A ello se unió el designio efectuado en aquella nación sobre un distinguido compatriota que abogó por nuestros intereses de modo temporal mientras los legados costarricenses se incorporaban formalmente a sus cargos.

Así, este artículo expone todas las circunstancias, personajes, fechas y factores que se conjugaron entre 1821 y 1823 sobre dicha temática, con ello se pretende explicar y contextualizar al lector sobre estos hechos que fueron resultado inmediato de la coyuntura independentista y que marcaron el derrotero histórico-político de Costa Rica durante los primeros años de su existencia soberana.

\section{LA ANTESALA AUTONOMISTA}

Tras el surgimiento del I Imperio Napoleónico en 1804, la invasión de la Grande Armée (fuerza armada francesa) contra España en 1808 (Pirenne, 1973 , p. 171) no solo provocó la desestabilización de la monarquía de ese territorio, sino que tuvo profundos impactos en Las Indias (antiguo nombre oficial del actual continente americano) (Zorraquín, 1988-1992, p. 


\section{DERECHO ELECTORAL}

61) las cuales se encontraban bajo la égida hispana desde finales del siglo $\mathrm{XV}$.

Así, para el momento en que las primeras noticias sobre la usurpación francesa llegaron a suelo indiano, sus incidencias provocaron la reactivación (en algunos casos) y el origen (en otros muchos) de múltiples episodios pro independentistas de diverso grandor. Tal fue el caso de lo acontecido en el llamado Virreinato de la Nueva España (Humboldt, 2014, pp. 3-7), cuya creación (1535) se había originado con el fin de que la Corona española ejerciese su autoridad, por interpósita mano, en una zona contenida entre el actual centro-oeste de los Estados Unidos y las regiones panameñas de Bocas del Toro y Chiriquí, con la Ciudad de México como capital, la cual, por su parte, había sido fundada en 1521 (Carrillo, 1985, pp. 28-30), tras la conquista de la metrópoli azteca-mexica de Tenochtitlán (Thomas, 2011, pp. 559-584).

Al respecto, después de dos años de eventos, fue en septiembre de 1810 cuando la gesta emancipadora novohispana comenzó en el poblado de Dolores (región de Guanajuato) por parte del presbítero Miguel Hidalgo y Costilla (Jinesta, 1951, p. 62), quien, tras arengar a sus habitantes y enarbolar un estandarte con la efigie de la Virgen de Guadalupe (Nebel, 1995, pp. 159-160), se dirigió a otras ciudades para expandir la lucha a la cual se incorporó de inmediato un multitudinario conjunto de seguidores. No obstante, Hidalgo fue ejecutado (julio, 1811) (Sotomayor, 2016, pp. 87-90), y asume, entonces, el mando superior el también sacerdote José M. Morelos y Pavón, quien dirigió la rebelión hasta diciembre de 1815 cuando también resultó asesinado (Tapia, 2008, p. 48); por lo que, se erige así el arriero Vicente Guerrero S., desde 1816, como el principal líder insurgente (Sosa, 2006, pp. 345-349).

Ya para finales de 1820 surgió la figura del militar Agustín de Iturbide Aramburu (Vázquez, 2007, pp. 112-114), quien, si bien es cierto comenzó luchando contra la rebelión, luego se unió a esta, tras pactar con Guerrero el denominado Plan de la Independencia de la América Septentrional o comúnmente llamado Plan de Iguala (febrero, 1821) (López, 2014, p. 20), en cuyas cláusulas se determinó que, en caso de vencer a los españoles, el territorio novohispano se reconfiguraría en una monarquía propia (precedida de una entidad direccional transitoria) y se emitiría una norma constitucional (Soberanes, 2014, p. 132). 


\section{DERECHO ELECTORAL}

Fue entonces, tras varios meses de nuevas luchas, cuando las autoridades españolas capitularon en Ciudad de México tras los llamados Tratados de Córdoba (agosto) (Krauze, 2009. p. 100), y fue el 28 de septiembre cuando se firmó en dicha capital el Acta de Independencia del Imperio Mexicano (Martín, 2011, p. 352), a lo que siguió la instalación, según el Plan de Iguala, de una Junta Provisional Gubernativa y un Consejo de Regencia. Órgano este último encabezado por Iturbide (Vadillo, 1990, pp. 89-103) y que se encargaría del poder monárquico interino hasta que se entronizase al futuro emperador de México. Mas los intereses geopolíticos de Iturbide no se circunscribieron a lo antes expuesto, pues casi de seguido empezó a planificar la expansión territorial de las fronteras mexicanas.

En ese sentido, el objetivo fue el denominado Reino de Guatemala (Molina, 1850, p. 14), el cual era una subentidad creada en 1543 dentro del Virreinato de la Nueva España que abarcaba a todas sus regiones australes para efectos político-administrativos; además, con funciones como Capitanía General (aspectos militares) y Real Audiencia (aspectos jurídicos), y cuya máxima frontera interna sur fue la llamada Provincia de la Nueva Cartago y la Costa Rica (fundada en 1540) (Sibaja, 2006, pp. 121-131), la cual, a partir de 1573, ostentó el nombre oficial de Provincia de Costa Rica (Meléndez, 1992, pp. 109-122). La estructura colonial anterior se mantendría incólume hasta la segunda década del siglo decimonónico.

Así, desde la ya citada invasión francesa a España y como una de las medidas que se adoptaron para repelerla, se convocó a representantes de las ciudades hispanas y las regiones indianas para que concurriesen a las llamadas Cortes (Volio, 1980, p. 20), es decir, las asambleas estamentales que, desde la Edad Media, se reunían para asuntos de importancia del reino hispánico. El órgano se ubicó en la ciudad sureña de Cádiz y, tras varios meses de trabajos, aprobó la llamada Constitución Política de la Monarquía Española (marzo, 1812) (Herrera, 2012, p. 20) o también denominada Constitución de Cádiz o Constitución Gaditana (por el gentilicio de los habitantes de esa localidad).

Esta norma se erigió como la primera de su tipo en territorio español, indiano y costarricense (Araya, 2005, pp. 11-19), y suprimió los antiguos virreinatos, con la creación, en su lugar, de las ahora llamadas provincias (dirigidas por un jefe político superior), las cuales estarían integradas por partidos (liderados por un jefe político subalterno), además de las 


\section{DERECHO ELECTORAL}

llamadas diputaciones provinciales para que coadyuvasen en el gobierno de las provincias (Sáenz, 1997, p. 96). Esto implicó que el virreinato novohispano pasase a conocerse ahora como la Provincia de Nueva España, mientras que el Reino de Guatemala, tras subir de rango, se convirtió en la Provincia de Guatemala. Asimismo, y por orden de las Cortes, se desafectó una porción del otrora Reino guatemalteco y se creó la nueva Provincia de Nicaragua y Costa Rica (mayo, 1812) (Zelaya, 1971, p. 28), cuya diputación provincial se ubicó en la ciudad de León, seguida de la instalación de la jefatura política subalterna del ahora Partido de Costa Rica en la ciudad de Cartago (noviembre, 1813).

Empero, el modelo gaditano estuvo vigente apenas dos años, pues tras la derrota de los franceses, el depuesto rey español Fernando VII regresó a su país en 1814 y derogó la Constitución de Cádiz (por considerarla una limitante a su otrora poder real), por lo que el antiguo andamiaje virreinal fue reinstaurado (Tomás, 1987, p. 442). Esto a su vez causó profunda indignación y furia entre gran cantidad de españoles e indianos que no estaban dispuestos a volver al antiguo régimen omnímodo, por lo que se desató una nueva jornada emancipadora en ambos territorios, hasta que, para 1820, Fernando VII se vio compelido a restituir la vigencia de la Constitución Gaditana (Fortín, 2013, p. 232) y, en consecuencia, resurgieron las provincias de Nueva España, Guatemala y Nicaragua-Costa Rica.

Fue así como todos los acontecimientos acaecidos en España y México tuvieron gran repercusión en los territorios del antiguo Reino guatemalteco, pues provocaron la independencia de las provincias de Chiapas (8 de septiembre, 1821), Guatemala (15 de septiembre), San Salvador (actual El Salvador 21 de septiembre), Comayagua (actual Honduras, 28 de septiembre) y Nicaragua (11 de octubre) (O 'Gorman, 2012, p. 39; Dym, 2012, pp. 7-8; Mayes, 1956, pp. 49-50; Meléndez, 1971, pp. 265-272 y Obregón, 1995, pp. 20-21).

Mientras que, en lo referente a Costa Rica, tras una serie de incidencias internas y desligándose del nexo con la Diputación Provincial de León, nuestras autoridades, conjugadas en una Junta de Legados de los Ayuntamientos (Rodríguez, 1980, p. 35), decretaron nuestra autonomía el lunes 29 de octubre de 1821 (Chacón, 1979, pp. 19-25), tras la firma de la denominada Acta de Independencia de Costa Rica (Aguilar y Araya, 1971, p. 19), con lo cual se dio la ruptura político-jurídico formal de 


\section{DERECHO ELECTORAL}

nuestro territorio con la monarquía española tras poco más de tres siglos de unión (Arias, 2014, p. 3).

\section{Concatenación de INTERESes}

Como puede colegirse, fue precisamente para la misma época en que se dieron los procesos emancipadores centroamericanos, cuando también aconteció la ya descrita autonomía mexicana. Ocasión que, el ya también citado Gral. Agustín de Iturbide consideró propicia para proponer el proyecto de que todo el otrora Reino de Guatemala pasase a convertirse en parte del I Imperio mexicano, lo cual fue aceptado por casi todas las regiones de esa antigua entidad colonial.

Idea que en lo que atañe a Costa Rica ya había sido propuesta en nuestra acta independentista al señalarse en su artículo segundo: "Que absolutamente se observarán la Constitución y leyes que promulgue el Imperio Mexicano, en el firme concepto de que en la adopción de este plan consiste la felicidad y verdaderos intereses de esta Provincia..." (Comisión Nacional de Conmemoraciones Históricas, 1979, p. 9).

Así, tras la sustitución de la Junta de Legados de los Ayuntamientos por una Junta de Legados de los Pueblos (Arias, 2020, pp. 241-261), dicha entidad emitió, el $1 .^{\circ}$ de diciembre de 1821 (Fournier, 1978, p. 215), el Pacto Social Fundamental Interino de Costa Rica o también denominado Pacto de Concordia (Peralta, 1972, p. 14), el cual no solo fue nuestra primera norma fundamental propia (y segunda de nuestra historia, después de la Constitución Gaditana) (Arias, 2017, p. 91), sino que le dio a nuestro país la condición político-jurídica de provincia.

Ya para enero de 1822, la Junta de Legados de los Pueblos fue sucedida por una Junta Electoral (Obregón, 2000, p. 47), la cual modificó el texto del Pacto de Concordia (10 de enero) (Miranda, 2017, p. 26), cuyo nuevo artículo $1 .^{\circ}$ indicó: "La Provincia de Costa Rica está decidida a su unión con el Imperio Mexicano y enviará a las Cortes de México, el Diputado o Diputados que se le señalen y se sujetará a la Constitución que aquel Soberano Congreso establezca..." [el subrayado no es del original] (Obregón, 2007, p. 108), con lo cual nuestro territorio pasó a formar parte nominal de dicha entidad imperial mexicana, pues ello se supeditó al cumplimiento de varios requisitos previos. Hecho al que siguió la instalación de una Junta Superior Gubernativa (González, 1936, p. 89) 


\section{DERECHO ELECTORAL}

para que asumiese el mando político de Costa Rica en lugar de la Junta Electoral.

Fue entonces durante esa precisa coyuntura cuando aconteció la escogencia de los legados de la Provincia de Costa Rica ante el I Imperio mexicano, lo cual sucedió en dos escenarios políticos muy distintos. Ya que, por una parte, la Junta Provisional Gubernativa que regía en México desde 1821 y que había desaparecido tras la instalación del primer Congreso Constituyente de ese país (febrero, 1822) (Frasquet, 2009, p. 57) decretó que, mientras arribaban a Ciudad de México los representantes de las provincias centroamericanas, se escogiese a individuos originarios de esas regiones y que estuviesen domiciliados en suelo mexicano, para que fungiesen como diputados interinos de sus respectivas patrias hasta que los titulares pudiesen incorporarse a los trabajos del Congreso mencionado (Sáenz, 2020, p. 116). Mientras que, por otro lado, la Junta Superior Gubernativa se abocó en Costa Rica a la determinación de nuestros dos enviados ante dicha entidad mexicana.

Fueron procesos eleccionarios de ostensibles efectos para nuestro territorio, pues ello devino en la escogencia en Costa Rica, el 10 de marzo de 1822, de los sacerdotes José Francisco de Peralta y López del Corral (propietario) y José Antonio Alvarado Bonilla (suplente) (Peralta, 1968, p. 233); y en México, se dio el designio, el 22 de marzo de ese mismo mes, del Presb. Florencio José del Castillo Villagra (Arias, 2021, p. 28). Personajes cuyos derroteros previos se exponen a continuación:

a) Presb. Florencio J. del Castillo V.: Nacido en la ciudad cartaginesa de Ujarrás en 1778 (Arias, 2015, pp. 6-8), desde muy joven se trasladó a Nicaragua, donde ingresó al Semanario Conciliar de León y se ordenó como sacerdote (1802) (Solera, 1962, p. 143); laboró luego en esa misma institución como profesor de geometría. En 1806 regresó a Costa Rica y fungió como cura párroco de Villahermosa (actual ciudad de Alajuela) (Blanco, 1967, p. 301); hasta que en 1808 volvió a suelo nicaragüense para trabajar como examinador sinodal, promotor fiscal y vicerrector de la referida entidad seminarista de León (González, 2015, pp. 2931).

En 1810 y como resultado de la escogencia para diputados de las Cortes de Cádiz, se le designó para representar a Costa Rica ante dicho ente (Archivos Nacionales, 1918, pp. 395-396), por lo que le 


\section{DERECHO EIECTORAL}

correspondió no solo ser uno de los firmantes de la Constitución de Cádiz (De Tapia, 1961, pp. 13-38), sino que, para valía suya y de nuestro territorio, ocupó el distinguido cargo de presidente de esa asamblea constituyente hispano-indiana (1813) (Arias, 2011, pp. 287-317).

Fue entonces en 1814 y como resultado de varias recomendaciones, cuando del Castillo fue elegido canónigo (autoridad del cabildo eclesiástico) de la Catedral de Oaxaca (Fernández, 1937, p. 528), y viajó al Virreinato de la Nueva España ese mismo año para ocupar el puesto de cita. Ya para 1821, el Obispado de Oaxaca lo designó como su representante ante una junta de autoridades eclesiásticas (Benavides, 2013, pp. 54-61) convocada en Ciudad de México por el Gral. Agustín de Iturbide para regir las relaciones políticas entre la Iglesia mexicana y el ya mencionado Consejo de Regencia; y en 1822 resultó electo por la Junta Provisional Gubernativa de esa nación como diputado interino por la Provincia de Costa Rica ante el Congreso Constituyente mexicano.

b) Presb. José F. de Peralta y L.: Su nacimiento aconteció en la ciudad de Cartago (1786) (Cascante y Sáenz, 2008, p. 5). En su juventud se dirigió a Nicaragua y se convirtió en sacerdote (1811), luego viajó a El Salvador para desempeñarse como párroco de la ciudad de Olocuilta (1819) (Lobo, 2015, p. 78). Para los primeros meses de 1822 y cuando se encontraba residiendo en Ciudad de Guatemala, recibió de la Junta Superior Gubernativa su nombramiento como diputado titular de la Provincia de Costa Rica ante la Asamblea Constituyente del I Imperio mexicano.

c) Presb. José A. Alvarado B.: Tras nacer en la ciudad de Cartago (1779), emprendió un largo periplo hasta Ciudad de Guatemala donde obtuvo la condición sacerdotal y laboró como cura párroco de la ciudad de Mazatenango (Lobo, 2015, p. 8); estando en dicha localidad, la Junta Superior Gubernativa le informó, en 1822, sobre su designio como diputado suplente del Congreso Constituyente de México por parte de su natal Provincia de Costa Rica. 


\section{DERECHO ELECTORAL}

\section{DisOLUCIÓN INEXORABLE}

Como ya se ha dicho, la unión política entre Costa Rica y México quedó sujeta a una serie de requerimientos que nuestro territorio exigió como paso previo a la formalización de dicho nexo. Este hecho empezó a tornarse incierto, desde mayo y junio de 1822, cuando Agustín de Iturbide logró que el Congreso Constituyente de su país le confiriese la condición de emperador de México (Riva, 1979, pp. 75-78), así, fue coronado con el nombre de Agustín I (Villalpando y Rosas, 2003, p. 131) en una ceremonia entre cuyos eclesiásticos oficiantes estuvo el Presb. Florencio del Castillo, quien, además, fue nombrado como parte del novel Consejo de Estado de Iturbide (Sotela, 1942, p. 7).

Para septiembre de 1822 nuestras autoridades le remitieron al Presb. José F. de Peralta el pliego de condiciones que este debía presentar cuando se apersonase al Congreso Constituyente mexicano (Fernández, 1971, p. 36), las cuales también le fueron enviadas al Presb. del Castillo para que estuviese al tanto de ellas.

Sin embargo, la situación política en México se enturbió, pues, desde su coronación, Agustín I empezó a incurrir en varios actos despóticos que no solo provocaron su distanciamiento respecto de sus antiguos compañeros de armas, sino que, incluso, lo enemistaron con gran parte del Congreso Constituyente. Esto llegó a su clímax cuando Iturbide disolvió unilateralmente a dicha entidad colegiada (octubre, 1822) (Ávila, 2008, p. 44) y creó en su lugar una Junta Nacional Instituyente (noviembre) (Margadant, 2001, p. 148); órgano en el que el sacerdote Peralta permaneció como representante de Costa Rica, mientras que el Presb. del Castillo solo siguió como parte del Consejo de Estado imperial y mantuvo correspondencia con nuestras autoridades (Llorente, 2020, p. 343-345).

Lo anterior hizo que para enero y febrero de 1823 (cuando nuestro territorio era ya gobernado por una segunda Junta Superior Gubernativa) (Monge, 1955, p. 143) y tras enterarse de las tropelías de Iturbide, una gran cantidad de habitantes empezasen a cuestionar con vehemencia el vínculo con México (Fernández, 1984, p. xxxx), a lo que siguieron múltiples petitorias para disolverlo, dada la perenne omisión que las autoridades imperiales mexicanas habían efectuado respecto de los requisitos solicitados por Costa Rica desde septiembre de 1822 (Cerdas, 1985, p. 119). Fue así como se convocó a un Congreso Provincial (primero de nuestra historia) (Díaz, 2019, p. 22) para que se dilucidase el destino 


\section{DERECHO ELECTORAL}

político de Costa Rica, cuyos integrantes, tras analizar una serie de pareceres y bemoles, procedieron a derogar, el 8 de marzo de 1823 (Sáenz, 1996, p. 24), la unión con el I Imperio mexicano, tras poco menos de catorce meses de vigencia. A lo que siguió la supresión del Pacto de Concordia y la aprobación, en su lugar, del llamado Primer Estatuto Político de la Provincia de Costa Rica (19 de marzo) (Zeledón, 1946, pp. 17-21), cuyo texto se convirtió en la tercera norma fundamental de nuestra historia (Peralta, 1962, pp. 147-155).

En esa última fecha, por exacta coincidencia histórica, feneció el I Imperio mexicano, pues tras una contundente rebelión en su contra (iniciada en diciembre de 1822) (Alvear, 1964, pp. 260-261), Agustín I se había visto compelido a restaurar al disuelto Congreso Constituyente (4 de marzo, 1823), y a presentar luego su renuncia el 19 de marzo de cita (Padilla, 1992, p. 13), con lo cual dicho régimen imperial se disolvió después de dieciocho meses de duración.

\section{LOS DESTINOS ULTERIORES}

Tras los hechos narrados, cada uno de los tres representantes de la Provincia de Costa Rica ante el I Imperio mexicano protagonizaron distintos derroteros hasta el término de sus vidas.

Así, en lo concerniente al Presb. José F. de Peralta, este finalmente nunca viajó a suelo mexicano para ocupar su curul; y a los pocos años y para el momento en que Costa Rica formó parte de la República Federal de Centroamérica, dicho religioso fue escogido como uno de nuestros diputados ante esa entidad regional (1825-1826); también fungió como miembro de su Senado (1829-1830). Asimismo, se desempeñó como diputado en el Congreso de Costa Rica por los poblados de Boruca y Térraba (1823 y 1838), Ujarrás (1828-1829) y Santa Cruz (1832-1834) (Stone, 1976, p. 547), en ese último bienio también ejerció el cargo de presidente de dicho órgano legislativo (Obregón, 1995, p. 66). En 1835 fue uno de los principales soliviantados en la Guerra de la Liga que enfrentó a las ciudades de Cartago, Alajuela y Heredia contra la de San José (Montero, 1892, pp. 226-237), razón por la que, tras la victoria de la capital, se exilió, y regresó a Costa Rica en 1842 para apoyar al sedicioso Gral. Francisco Morazán Q. en el golpe de Estado que perpetró contra el gobernante Braulio Carrillo Colina (Obregón, 1981, pp. 55-57). En esa misma época fue electo diputado por Cartago para una Asamblea 


\section{DERECHO ELECTORAL}

Constituyente convocada por Morazán y se le escogió como presidente de esa entidad (julio, 1842) (Fernández, 1984, p. 45), donde fue el artífice del proyecto de ley para la fundación de un colegio en esa ciudad bajo el patronazgo religioso de San Luis Gonzaga (septiembre, 1842), el cual se inauguró en 1869 (González, 1978, p. 384). Para 1844 volvió a fungir como diputado por Cartago, pero su muerte acaeció durante ese mismo año y en ese mismo lugar como resultado de una fortísima caída que sufrió durante una cabalgata (Lobo, 2015, p. 78); fue sepultado en el cementerio de ese mismo sitio.

Por su parte, aunque el Presb. José Alvarado B. no ejerció acción alguna como diputado suplente de la Provincia de Costa Rica, con posterioridad, sí fungió, entre 1823 y 1824, como uno de nuestros representantes (Obregón, 2007, p. 62) en la Asamblea Nacional Constituyente que emitió, en noviembre de ese año, la Constitución Política de la República Federal de Centroamérica (quinta norma de nuestro acervo constitucional) (Zeledón, 1941, p. 1); así como el puesto de senador por Costa Rica en el primer Congreso Federal de ese órgano (1824). Murió en Ciudad de Guatemala en 1832 (Lobo, 2015, p. 8).

Mientras que, en lo atinente al Presb. Florencio del Castillo, tras el colapso del I Imperio mexicano, se reincorporó a su puesto canonical en la Diócesis de Oaxaca. En años posteriores desempeñó una ostensible serie de cargos públicos en ese Estado, tales como los de diputado y presidente de su primer Congreso (1823), diputado y presidente de su primer Congreso Constituyente (1824), cofirmante de su primera Constitución Política (1825), primer catedrático de Derecho Constitucional (18251834), integrante de su Junta Calificadora de Imprenta (1827), diputado de su segundo Congreso (1827-1829) y coautor de su primer Código Civil (1827-1829) (Álvarez, 1977, p. 975; Martínez, 2009, p. 593; Solera, 1971, p. 12 y Cruz, 2010, p. 48). Desde 1830, le correspondió fungir en el honroso puesto de director del Instituto de Ciencias y Artes de Oaxaca (Arias, 2020, p. 15), donde presidió, como parte de sus funciones académicas, el tribunal calificador que le concedió el título de bachiller en Jurisprudencia (actual carrera de Derecho) a un joven oaxaqueño de 24 años que llegaría a convertirse en uno de los presidentes más afamados de México: Benito P. Juárez García (Vargas, 2007, p. 84). En paralelo, en 1830 también ejerció como canónigo chantre (dirigente principal del coro) de la Catedral de Oaxaca (Duran, 2003, p. 78) y, a partir de 1834, como gobernador de la Sagrada Mitra (máxima autoridad interina) del Obispado oaxaqueño (Vinatea y Fernández, 2011, p. 40). Su muerte acaeció en la 


\section{DERECHO EIECTORAL}

ciudad de Oaxaca en noviembre de ese mismo año (Bonilla, 1967, p. 58.), tras lo cual se le inhumó en el templo capuchino de San José de esa misma localidad mexicana, y su osamenta fue repatriada en 1971 (Malavassi y Gutiérrez, 1992, p. 54) y declarado Benemérito de la Patria en 1972 (Zeledón, 2013, p. 440).

Así, si bien es cierto la unión política entre la Provincia de Costa Rica y el I Imperio mexicano transitó por una serie de momentos álgidos que al final dieron al traste con dicho nexo, también resulta verdadero que nuestro territorio contó durante esa coyuntura histórica con tres ilustres individuos que fungieron (en el caso del Presb. del Castillo) y estuvieron a punto de hacerlo (en el de los religiosos Peralta y Alvarado) a favor de los más caros intereses costarricenses. Por lo que, al estarse conmemorando en 2021 el bicentenario de nuestra gesta independentista, resulta imperioso que no solo se rememore las figuras de quienes propiciaron dichos eventos dentro de nuestro país, sino también la de aquellos compatriotas que desarrollaron una valiosa y prolífica variedad de acciones en esa misma época fuera de nuestro territorio.

\section{REFERENCIAS BIBLIOGRÁFICAS}

Aguilar, O. y Araya, C. (1971). Breve reseña del desarrollo político- constitucional de Costa Rica en 150 años de Independencia. En: El desarrollo nacional en 150 años de vida independiente. San José: Universidad de Costa Rica y Comisión Nacional del Sesquicentenario de la Independencia de Centroamérica.

Álvarez, J. (1977). Enciclopedia de México. México D. F.: E. de México S. A.

Alvear, C. (1964). Historia de México. México D. F.: Editorial JUS.

Araya. C. (2005). Historia del Derecho Constitucional Costarricense. San José: EUNED.

Archivos Nacionales (1918). Índice de los protocolos de Cartago (1785-1817) (tomo V). San José: Imprenta Nacional.

Arias. T. (2011). La Masonería y la Constitución Gaditana (Presb. Florencio del Castillo y Presb. Francisco Calvo). En: Academia de Geografía e Historia de Costa Rica. La Constitución de Cádiz y Florencio del Castillo: legado de una época. San José: EUNED.

Arias, T. (2014). Independencia de Costa Rica: hecho histórico-jurídico. Boletín informativo de la Contraloría General de la República, n. 06. 


\section{DERECHO EIECTORAL}

Arias, T. (2015). 150 años de historia de la Masonería en Costa Rica. San José: ECR.

Arias, T. (2017). Historia de las logias masónicas de Costa Rica (siglos XIX, XX y XXI). San José: ECR.

Arias, T. (2020). Don Manuel María de Peralta y Corral (1791-1837): legado suplente por Esparza. En: Sáenz, J. y otros (Eds.), Los Padres de la Constitución (los firmantes del Pacto de Concordia). San José: Ministerio de Relaciones Exteriores y Culto e Instituto del Servicio Exterior.

Arias, T. (2020). México y Centroamérica: historia bilateral milenaria. Revista Estudios, (41).

Arias, T. (2021). Historia de las relaciones diplomáticas entre la República de Costa Rica y los Estados Unidos Mexicanos. Revista Costarricense de Política Exterior, n. ${ }^{\circ} 35$.

Ávila, A. (2008). El gobierno imperial de Agustín de Iturbide. En: W. Fowler, Gobernantes mexicanos (tomo I; 1821-1910). México D. F.: FCE.

Benavides, M. (2013). El canónigo Florencio Castillo (sus luces en un México independiente y federal). San José.

Blanco, R. (1967). Historia eclesiástica de Costa Rica, San José: ECR.

Bonilla, A. (1967). Historia de la literatura costarricense. San José: ECR.

Carrillo, R. (1985). Historia de la Ciudad de México, México D.F.: Pan. Editorial.

Cascante, C. y Sáenz, J. (2008). Ad Ardua Per Alta: una biografía del Marqués de Peralta. San José: EUCR.

Cerdas, R. (1985). Formación del Estado en Costa Rica (1812-1842). San José: EUCR.

Comisión Nacional del Sesquicentenario de la Independencia de Centroamérica. (1971). Actas del ayuntamiento de Cartago (1820-1823). San José: Imprenta Nacional.

Cruz, O. (2010). La codificación en México, México D.F.: Editorial Porrúa.

Chacón, L. (1979). Acta del 29 de octubre de 1821: nuestra independencia de España. En Comisión Nacional de Conmemoraciones Históricas, Acta de la Independencia absoluta de Costa Rica del Gobierno español (29 de octubre de 1821). San José: Imprenta Nacional.

De Tapia, E. (1961). Luz y taquígrafos (un siglo de Parlamento en España). Madrid: Editorial Aguilar.

Díaz, D. (2019). La vida política: 1808-2000. En: P. Vega, Historia contemporánea de Costa Rica (1808-2010). San José: Fundación MAPFRE, ECR y EUNED. 


\section{DERECHO EIECTORAL}

Durán, J. (2003). Senderos de identidad (diez ensayos literatura costarricense). San José: ECR.

Dym, J. (2012). Actas de Independencia: de la Capitanía General de Guatemala a la República Federal de Centroamérica. En D. Díaz R. Viales, Independencias, Estados y políticas en la Centroamérica del siglo XIX. San José: CIHAH.

Fernández, R. (1937). Don Florencio del Castillo. Revista de los Archivos Nacionales, n. ${ }^{\circ}$ 9-10.

Fernández, R. (1971). La Independencia. San José: Comisión Nacional de Sesquicentenario de la Independencia de Centroamérica.

Fernández, R. (1984). Cartilla histórica de Costa Rica. San José: Imprenta Lehmann.

Fortín, R. (2013). La influencia de la Constitución gaditana en América Latina. En D. Barceló y J. Serna de la Garza, Memoria del seminarito internacional: conmemoración del bicentenario de la Constitución de Cádiz (las ideas constitucionales de América Latina). México D.F.: UNAM.

Fournier, F. (1978). Historia del Derecho. San José: Editorial Juricentro.

Frasquet, I. (2009). De la autonomía provincial a la República Federal. México: 18201824. Ayer (Asociación de Historia Contemporánea), (74).

González, L. (1978). Evolución de la instrucción pública en Costa Rica. San José: ECR.

González, L. (2015). La Universidad de León y el presbítero Florencio del Castillo. En E. Zeledón, Luis Felipe González Flores: Textos históricos, educativos y biográficos (tomo II). Heredia: EUNA.

González, C. (1936). Personal del Poder Ejecutivo de Costa Rica (1821-1936). Revista de los Archivos Nacionales, (1-2).

Herrera, M. (2012). De vasallos a ciudadanos: Bicentenario de la Constitución de Cádiz. San José: MCJ, Archivo Nacional y Consejería Cultural de la Embajada de España en Costa Rica.

Humboldt, A. (2014). Ensayo político sobre el reino de la Nueva España. México. D.F., Editorial Porrúa.

Iglesias, F. (2020). Documentos relativos a la Independencia (tomo III). San José: EUNED.

Jinesta, C. (1951). Evocación de Hidalgo. México D.F.: Editorial Pluma y lápiz de México.

Krauze, E. (2009). Siglos de caudillos. México D.F.: Maxi Tusquets Editores.

Lobo, O. (2015). Sacerdotes diocesanos y religiosos en Costa Rica: 1800-2015. San José. 


\section{DERECHOEIECTORAL}

López, E. (2014). El Derecho en México. México D.F.: Editorial Porrúa.

Malavassi, G. y Gutiérrez, P. (1992). Diccionario biográfico de Costa Rica. San José: UACA.

Margadant, G. (2001). Introducción a la Historia del Derecho mexicano. Estado de México: Editorial Esfinge.

Martín, F. (2011). 100 mitos de la historia de México (tomo I). México. D. F.: Santillana.

Martínez, F. (2009). Introducción al Derecho parlamentario de Oaxaca (estudio monográfico del Congreso del Estado libre y soberano de Oaxaca. En E. Chaves, Introducción al Derecho parlamentario estatal. México D. F.: UNAM.

Mayes, G. (1956). Honduras en la Independencia de Centroamérica y la anexión a México. Tegucigalpa: Tipografía Nacional.

Meléndez, C. (1971). Textos fundamentales de la Independencia centroamericana. San José: EDUCA.

Meléndez, C. (1992). Reales cédulas relativas a la Provincia de Costa Rica (1540-1802). San José: Comisión Nacional de Conmemoraciones Históricas.

Miranda, H. (2017). La independencia jurídica de Costa Rica con respecto a las leyes españolas y de indias durante el período de 1821 a 1841 . San José: EDINEXO.

Molina, F. (1850). Memoria sobre las cuestiones de límites que se versan entre la República de Costa Rica y el Estado de Nicaragua. Madrid: Imprenta de la viuda de Calero.

Monge, C. (1955). Historia de Costa Rica. San José: Imprenta Las Américas.

Montero, F. (1892). Elementos de Historia de Costa Rica. San José: Tipografía Nacional.

Nebel, R. (1995). Santa María Tonantzin Virgen de Guadalupe. México D.F.: FCE.

Obregón, R. (1981). Hechos militares y políticos. Alajuela: MHCJS.

Obregón, R. (1995). El Poder Legislativo en Costa Rica. San José: Asamblea Legislativa.

Obregón, C. (2000). El proceso electoral y Poder Ejecutivo en Costa Rica. San José: EUCR.

Obregón, C. (2007). Las Constituciones de Costa Rica (tomo I). San José: EUCR.

O 'Gorman, E. (2012). Historia de las divisiones territoriales de México. México D.F.: Edit. Porrúa. 


\section{DERECHO EIECTORAL}

Padilla, R. (1992). Historia de la política mexicana. México D.F.: EDAMEX.

Peralta, H. (1962). Las Constituciones de Costa Rica. Madrid: Instituto de Estudios Políticos.

Peralta, H. (1968). Agustín de Iturbide y Costa Rica. San José: ECR.

Peralta, H. (1972). El Pacto de Concordia. San José: Editorial Lehmann.

Pirenne, J. (1973). Historia Universal (tomo 5). Barcelona: Editorial Éxito.

Riva, V. (1977). México a través de los siglos (tomo IV). México D. F.: Editorial Cumbre.

Rodríguez, E. (1980). Biografía de Costa Rica. San José: ECR.

Sáenz, J. (1996). Historia diplomática de Costa Rica (t. I). San José: Editorial. Juricentro.

Sáenz, J. (1997). Historia del Derecho costarricense. San José: Editorial Juricentro.

Sáenz, J. (2020). Nicolás Carrillo y Aguirre (Presidente de la primera Constituyente de Costa Rica). San José: Ministerio de Relaciones Exterior y Culto e Instituto del Servicio Exterior.

Sibaja, L. (2006). El cuarto viaje de Cristóbal Colón y los orígenes de la provincia de Costa Rica. San José: EUNED.

Soberanes, L. (2014). Historia del Derecho mexicano. México D.F.: Editorial Porrúa.

Solera, G. (1962). Los grandes constructores de América. San José: Antonio Lehmann Librería e Imprenta.

Solera, G. (1971). Ilustres servidores de la enseñanza. San José: Imprenta. Nacional.

Sotela, R. (1942). Escritores de Costa Rica. San José: Imprenta Lehmann.

Sosa, F. (2006). Biografías de mexicanos distinguidos. México D.F.: Editorial Porrúa.

Sotomayor, J. (2016). Magnicidios y ocasos históricos en México. México D.F.: Editorial Porrúa.

Tapia, M. (2008). 101 héroes en la Historia de México. México D.F.: Grijalbo.

Stone, S. (1976). La dinastía de los conquistadores. San José: EDUCA.

Thomas, H. (2011). La conquista de México. México D.F.: Editorial Planeta Mexicana.

Tomás, F. (1987). Manual de Historia del Derecho español. Madrid: Editorial TECNOS.

Vadillo, G. (1990). El efímero imperio de Iturbide. Grandeza en la Historia, (37). 


\section{DERECHO EIECTORAL}

Vargas, A. (2008). El evangelio de don Florencio. San José: Editorial Juricentro.

Vázquez, J. (2007). Diccionario de Gobernantes y Héroes Nacionales de México (13252006). México D.F.: Grupo Patria cultural.

Villalpando, J. y Rosas, A. (2003). Historia de México a través de sus gobernantes. México D.F.: Editorial Planeta Mexicana.

Vinatea, J. y Fernández, R. (2011). Grandes familias de Costa Rica (historia, reseña, heráldica y biografía), San José, C.R.: Prints Publicidad.

Volio, M. (1980). Costa Rica en las Cortes de Cádiz. San José: Editorial Juricentro.

Zelaya, Ch. (1971). Nicaragua en la Independencia. San José: EDUCA.

Zeledón, E. (2013). Biografías costarricenses. Heredia: EUNA.

Zeledón, M. (1941). Reseña Histórica del régimen constitucional de Costa Rica. San José: Imprenta Nacional.

Zeledón, M. (1946). Digesto constitucional de Costa Rica. San José: Colegio de Abogados.

Zorraquín, R. (1988-1992). Estudios de Historia del Derecho. Buenos Aires: Editorial Abeledo-Perrot. 